\title{
Corpo e identidade: reflexões acerca da vivência de amputação
}

\author{
Body and identity: reflections about \\ life after amputation
}

\author{
Gabriela Bruno GALVÁN' \\ Maria Lúcia Toledo Moraes AMIRALIAN ${ }^{1}$
}

\begin{abstract}
Resumo
A amputação de um membro pode ser considerada um evento traumático diante da mudança brusca que ocasiona na vida de um indivíduo. Este artigo traz reflexões que surgiram a partir do atendimento psicológico a pacientes amputados em decorrência de algum tipo de acidente. O objetivo é refletir acerca das consequências psíquicas relacionadas a uma alteração súbita na dimensão corporal. Buscou-se compreender de que ordem é o abalo sofrido com esta perda física e como isto se articula com o caminho percorrido por todos os indivíduos ao longo do desenvolvimento, particularmente no que diz respeito à identidade e à integração psicossomática. Para isso, utilizou-se como embasamento teórico a psicanálise winnicottiana, mais especificamente, a constituição do si mesmo na teoria do amadurecimento pessoal.
\end{abstract}

Unitermos: Amputação. Psicanálise. Winnicott.

\begin{abstract}
The amputation of a limb may be considered a traumatic event in the face of the sudden changes in a person's life. This article introduces reflections arising from the psychological care given to amputees as a result of any type of accident. The purpose is to reflect about the psychological consequences related to the sudden change in bodily dimensions. It is also an attempt to comprehend the kind of disturbance suffered by this physical loss and how it is linked to the path all individuals tread over the course of the development, with particular regard for identity and psychosomatic integration. For this purpose, Winnicottian Psychoanalysis is used as the theoretical basis, more specifically, the creation of the self in the individual development theory.
\end{abstract}

Uniterms: Amputation. Psychoanalysis. Winnicott.

Este artigo propõe refletir sobre as implicações psíquicas diante de uma mudança brusca na constituição física de um indivíduo. Particularmente, são reflexões que foram surgindo no atendimento psicológico a pacientes que tiveram amputada uma parte do corpo, como consequência de algum tipo de acidente,

Há muitos fatores a serem considerados quando se pretende compreender mais profundamente as repercussões emocionais de uma perda tão significativa

$\boldsymbol{\nabla \nabla \nabla v}$

1 Universidade de São Paulo, Instituto de Psicologia. Av. Prof. Mello Moraes, 1721, Bloco D, Sala 227, Cidade Universitária, 05508-900, São Paulo, SP, Brasil. Correspondência para/Correspondence to: G.B. GALVÁN. E-mails: <gabrielagalvan@terra.com.br>; <galvan@usp.br>. 
como a de uma parte do corpo. O principal deles diz respeito às diversas constituições individuais e seu reflexo na forma de elaboração de uma perda física e suas consequências psíquicas.

Para encaminhar esta questão é fundamental delimitar a perspectiva teórica sob a qual se compreende o desenvolvimento emocional - neste caso, a psicanálise winnicottiana, que tem como base a teoria do amadurecimento pessoal. Essa teoria possui particularidades que diferem dos pressupostos psicanalíticos freudianos e que foram estudadas profundamente e descritas por vários autores, entre eles Dias (2003), Loparic (2005, 2006), Moraes (2005) e Fulgencio (2006).

Para Winnicott, diferentemente da psicanálise freudiana, não é com base em uma relação triangular, o Complexo de Édipo, que se dá a constituição do indivíduo. Na perspectiva winnicottiana, um ser se constitui a partir de uma relação dual; ele vem ao mundo com uma tendência inata para continuar a existir, integrar-se e amadurecer. Para isso, é necessário um ambiente que facilite a realização dessa tendência. Assim, é na relação mãe-bebê e não na relação triangular que Winnicott compreende a constituição do ser humano, como um percurso que, na saúde, permite ao indivíduo alcançar uma identidade, um si mesmo integrado. Desta forma, os conflitos relativos à sexualidade e às relações triangulares somente são considerados enquanto fatores relacionados ao adoecimento psíquico, uma vez que trata-se de pessoas inteiras, já constituídas. Antes disso, é através da compreensão do processo de amadurecimento emocional de cada pessoa que é possível entender o adoecimento.

Pode-se dizer que a teoria do amadurecimento pessoal tem um caráter relacional, uma vez que está voltada para a integração entre indivíduo e ambiente e o desenvolvimento possível a partir desta relação. Nesse sentido, o ser humano não é concebido como um ser em busca de satisfação/prazer, às voltas com os conflitos internos decorrentes de sua instintualidade, mas como um ser relacional, em busca da continuidade da existência.

A implicação disso em termos de compreensão do adoecimento psíquico é que aquilo que está perturbado no adoecimento é o amadurecimento emocional, considerando o desenvolvimento da sexualidade como parte desse amplo processo; o ambiente tem um papel fundamental na saúde e na doença do indivíduo (Loparic, 2006).

Assim, nesta concepção, o conceito de saúde refere-se à realização da tarefa principal do ser humano, entendida como a possibilidade de se tornar um indivíduo e amadurecer, enfrentando todas as dificuldades intrínsecas a esta tarefa, sem perder a essência da existência a partir da criatividade pessoal.

A teoria do amadurecimento pessoal é permeada pelo princípio de que o ser humano nasce dotado de uma tendência ao amadurecimento, que garante, na presença de um ambiente facilitador, a continuidade do ser. Qualquer parada nesse "continuar a ser" caracteriza aquilo que é considerado doença.

Se todo indivíduo é dotado de uma tendência inata ao amadurecimento, a doença consiste no bloqueio dessa tendência, em sua paralisação. Na saúde, o ser humano caminha ao longo de uma linha de desenvolvimento, contanto que exista um ambiente adequado para a realização do caminho em direção à integração e à constituição da personalidade. Por outro lado, a doença psíquica refere-se a um tipo de imaturidade, relativa a uma parada no desenvolvimento.

Winnicott (1961/2005, p.266), estabelece, ainda que de forma esquemática, três categorias de "imaturidade pessoal". Uma delas diz respeito a falhas ambientais que ocorreram no início da vida do bebê, ocasionando "uma perturbação na estrutura básica da personalidade do indivíduo" Nesse caso, trata-se de pessoas não integradas. O resultado pode ser "uma psicose infantil, ou dificuldades em estágios ulteriores podem ter exposto uma falha na estrutura do ego que tinha passado despercebida. Os pacientes nesta categoria nunca foram suficientemente saudáveis para tornarem-se psiconeuróticos".

Outra categoria é a que o autor chama de psiconeurose, e inclui a depressão, que faz parte do desenvolvimento normal do indivíduo. Nesta categoria estão os indivíduos que foram "suficientemente bem cuidados nos estágios iniciais da vida para terem condições, do ponto de vista do desenvolvimento, para enfrentar e, em certa medida, não conseguir conter as dificuldades que são inerentes à vida plena" (Winnicott, 1961/2005, p.266). Aqui, fala-se de pessoas inteiras, no sentido de que alcançaram o estágio de se tornar uma unidade e viver os conflitos referentes à instintualidade. 
A terceira categoria inclui "aqueles indivíduos que começaram suficientemente bem, mas cujo ambiente não os ajudou em algum ponto, ou repetidas vezes, ou durante um longo período de tempo" (Winnicott, 1961/2005, p.266). Essas pessoas experimentaram um ambiente suficientemente bom, mas que se perdeu e gerou como consequência uma interrupção no desenvolvimento emocional e um tipo de reivindicação manifesta em uma tendência antissocial. Essas categorias diagnósticas referem-se a falhas na estruturação do eu e em sua capacidade de se relacionar.

Particularmente no caso de pessoas que sofreram uma amputação, a importância do diagnóstico reside na necessidade de se compreender os recursos de que o indivíduo dispõe, em termos de amadurecimento emocional, para experienciar essa perda física. Além disso, a intervenção terapêutica dá-se considerando a fase em que o desenvolvimento emocional foi interrompido e oferecendo condições para que este seja retomado.

\section{A unidade como conquista}

A teoria winnicottiana do amadurecimento traz contribuições significativas para a compreensão da vivência de ruptura na integridade corporal. Para melhor entender esse momento de crise, é importante realizar um recorte mais específico no caminho que leva à constituição de um ser no sentido de um indivíduo integrado, que vive e se relaciona a partir de uma identidade própria.

O primeiro princípio a ser destacado, já apontado anteriormente, refere-se ao fato de que o indivíduo não nasce pronto e constituído. Winnicott aponta para uma tendência inata em direção à integração, porém só é possível que esse desenvolvimento ocorra diante de um ambiente facilitador. Assim, é por meio do holding materno que a criança pode começar a experimentar uma sensação de existência no tempo e integração de si mesma. Segundo Mello Filho (2001), o bebê funciona logo após o nascimento como se fosse um somatório de partes, necessitando do auxílio de uma maternagem adequada para, gradualmente, adquirir a noção de ser um todo coeso.

É necessário tomar como princípio básico a tendência herdada de cada novo indivíduo no sentido do crescimento e do desenvolvimento. Sob condições ambientais suficientemente boas, o indivíduo conduz, entre outras coisas, uma tendência no sentido da integração da personalidade (Winnicott, 1969/1994b, p.430).

Assim, em um primeiro momento, a dependência do bebê com relação ao ambiente é absoluta. Do ponto de vista do bebê não há dois; ele e o ambiente formam uma unidade. $O$ amadurecimento consiste na passagem para a dependência relativa e, finalmente, atingir o estágio da independência relativa. Em cada um desses momentos do amadurecimento a integração indivíduo e ambiente tem características próprias - isto porque as necessidades do indivíduo mudam à medida que ocorre o desenvolvimento rumo à autonomia. Porém, não significa que em algum momento se possa prescindir do outro; sempre existirá a necessidade de interação com o ambiente, uma vez que o ser humano se constitui e existe em relação com o outro. Isto aponta para uma das vertentes importantes na análise dos indivíduos que passaram a ter uma deficiência física (amputação): a forma de lidar com a dependência, que se torna explícita em termos de necessidade de cuidados físicos e auxílio na vida diária, muitas vezes vivida como perda na autonomia de ser.

Winnicott (1970/1994c, p.220) coloca o desenvolvimento emocional, em linhas gerais, da seguinte forma: a princípio, o bebê existe na dependência da figura materna, por meio da qual, em condições adequadas, vive uma experiência de onipotência. Vive, a seguir, uma posição intermediária, descrita detalhadamente na conceituação dos fenômenos transicionais e, "quando a externalidade foi estabelecida, acha-se pronto o caminho para um enriquecimento pessoal que não possui limites, baseado na experiência pessoal e fazendo uso dos mecanismos mentais que são usualmente chamados de projeção e introjeção".

É durante o período da dependência absoluta que o bebê, sustentado por um ambiente facilitador, necessita realizar o que se pode chamar de três "tarefas básicas", que naturalmente ocorrem simultaneamente: integração no tempo e no espaço, personalização (alojamento da psique no corpo) e início do contato com a realidade (externalidade)/início das relações objetais. Por meio da conjunção destes três processos, passa a existir um "eu" e um "não eu", um "dentro" e um 
"fora" e um esquema corporal: "O resultado desta interação de fenômenos éa possibilidade de o bebêalcançar o estágio de 'ser uma pessoa'"' (Mello Filho, 2001, p.47).

Para Winnicott (1945/2000b), a tendência à integração realiza-se a partir das experiências instintivas que tendem a aglutinar a personalidade a partir de dentro, em conjunto com o cuidado recebido do ambiente. A conquista da integração refere-se à possibilidade de ser um. Assim, o primeiro passo é a vivência do "eu" como diferente do "não eu"; a seguir, o enriquecimento do "eu" por meio da interação com o "não eu". Diz Winnicott (1962/1983, p.60): "Em circunstâncias favoráveis a pele se torna o limite entre o eu e o não-eu. Dito de outro modo, a psique começa a viver no soma e uma vida psicossomática de um indivíduo se inicia".

Isto significa que, ao nascer, soma e psique estão indiferenciados, de forma que a diferenciação e integração psicossomática são conquistas, desde que tudo corra bem no desenvolvimento do indivíduo. Como coloca Dias (2003, p.209):"Essa parceria psicossomática não está garantida nem pode ser dada como certa. Trata-se de uma conquista que pode - ou não - ser alcançada e que, tendo sido alcançada, pode ser perdida, mesmo na saúde". O corpo transforma-se em soma (corpo personalizado) e isto é feito por meio da elaboração imaginativa das funções corpóreas.

A primeira tarefa da psique é a elaboração imaginativa das funções corpóreas. No início, todas as experiências do bebê são corporais, vividas no corpo, por meio do corpo: o alimento, a sensação do banho na pele, a motilidade, a respiração, o cheiro da mãe, o calor do colo, a forma de ser ninado. Tudo é elaborado imaginativamente e, gradativamente, as funções psíquicas se aprimoram. É importante considerar que as funções mais complexas são alcançadas paralelamente e em decorrência da aquisição de outras funções necessárias ao desenvolvimento.

Loparic (2000) acrescenta que o soma, conforme descrito por Winnicott, não é o corpo físico: é o corpo vivo, com todas as suas possibilidades; desta forma, a tarefa inicial da psique é tornar o corpo personalizado, temporalizado e inserido em uma história simultaneamente pessoal e interpessoal. Outeiral (1991, p.126) enfatiza que a personalização significa a organização da trama psicossomática e que o corpo todo se torna o "lugar de residência do self".
Sob este ponto de vista, saúde pressupõe a existência de uma unidade psicossomática, que pode ser entendida como a integração das funções corpóreas e das funções psíquicas do indivíduo. Em termos fenomenológicos, isto se coloca como o sentimento de continuidade da existência, de estar dentro do próprio corpo e de se sentir"si mesmo", com uma personalidade completa e capaz de se relacionar com outras pessoas.

Costa (2004) sintetiza a formulação winnicottiana de unidade psicossomática quando afirma que a totalidade físico-psíquica é indissociável em condições psicológicas satisfatórias:

Dizer que suas "partes" são expressões parciais do todo quer dizer que cada uma delas resume e recapitula a história integral do sujeito. [Para Winnicott] o corpo no qual o eu se localiza não é apenas nem sobretudo o corpo erógeno. É o corpo que representa suas "funções" auto-reguladoras e suas "experiências" de interação com os objetos externos (1975:136), e, pela dupla representação, estabiliza o sentido de identidade do eu (Costa, 2004, p.108).

Safra $(2005$, p.79) também afirma que a unidade corporal é conquistada "por meio da e na presença do outro, surgindo paulatinamente um corpo psíquico: um corpo cujas funções foram elaboradas imaginativamente", e acrescenta que quando o desenvolvimento do self ocorre satisfatoriamente, as experiências tornam-se enriquecedoras para o seu self e para a sua relação com o outro.

Winnicott aponta para a evolução em termos de complexidade da elaboração imaginativa, e afirma que essa evolução pode não se dar integralmente, uma vez que ela ocorre como manifestação da tendência do ser humano para o amadurecimento, sendo que essa tendência necessita de condições favoráveis para se desenvolver. Em termos esquemáticos, o autor coloca o seguinte percurso em relação ao desenvolvimento da elaboração imaginativa:

1) Simples elaboração da função; 2) Distinção entre: antecipação, experiência e memória; 3) Experiência em termos de memória da experiência; 4) Localização da fantasia dentro ou fora do self, com intercâmbios e constante enriquecimento entre ambos; 5) Construção de um mundo interno, ou pessoal, com um sentido de responsabilidade pelo que existe e ocorre lá dentro; 6) Separação entre consciência e inconsciente (Winnicott, 1958/2001, p.10). 
Desta forma, ao mesmo tempo em que a elaboração da experiência enriquece e favorece o desenvolvimento do si mesmo, ao longo do próprio amadurecimento vão se criando as condições para abarcar e elaborar, em níveis mais complexos, as vivências tanto internas quanto referentes às relações interpessoais. Isto leva a pensar que a ruptura que se observa em um indivíduo que teve uma parte de seu corpo amputada pode ser da ordem de um abalo na unidade psicossomática, com consequências em toda a forma peculiar de "ser no mundo". Ao mesmo tempo, é possível perceber que a dificuldade na elaboração e integração da perda de uma parte do corpo não está relacionada unicamente à intensidade da perda propriamente dita e às mudanças concretas que ocorrem no corpo e na vida do indivíduo, mas também há que se considerar os entraves pessoais decorrentes de graus variados de imaturidade emocional anteriores ao momento da amputação.

\section{A perda de uma parte do corpo}

Muitas pessoas, após a amputação, deparam-se com um profundo sentimento de estranhamento de si mesmas: não se reconhecem nem fisicamente nem no que diz respeito às suas reações emocionais. A vivência descrita é de profunda angústia e indefinição com relação ao futuro, às capacidades e às limitações que estão sendo vividas, como se pode ver na fala de um paciente: "Eu não era assim, agora não sei o que fazer da minha vida... quando estou sentado sou eu mesmo, mas quando tenho quelevantartudo muda, écomo senão fosse eu". O tema principal parece se referir a um desmoronamento na vida e na identidade do indivíduo: nada permanece como era anteriormente ao acidente.

Rogério ${ }^{2}$ foi atropelado por um carro desgovernado e, como consequência, teve amputada uma perna. Na primeira entrevista, ele falou sobre o acidente e demonstrou seu desespero por ter perdido a perna. Estava tomado por uma impossibilidade de se ver sem a perna. Era como se nada mais existisse, somente a angústia de estar amputado. Em sua fala não havia história, não havia passado, não havia futuro. Havia somente o tempo a partir do acidente, vivido como um desmoronamento de seu mundo. Na segunda entrevista, Rogério contou sobre a sua vida antes do acidente, seu trabalho, os conflitos existentes entre sua família e sua esposa, que haviam ocasionado distanciamento em relação a seus pais e irmã. Era policial e, em seu trabalho, já vira várias pessoas que haviam sofrido acidentes como o dele e ficaram com sequelas graves e incapacitantes: "Eu sempre pensava: como o cara pode viver assim?". Enquanto estava internado, conversou com a psicóloga da Polícia Militar e Ihe disse que estava bem, confiante, esperava colocar uma prótese e ficar bem: "Ela acreditou eliberou minhas duas armas, aí cheguei em casa e minha mulher escondeu a munição, ela falou que não adiantava procurar porque estava muito bem escondida, que eu ia ter que procurar outro jeito". Tomou todos os remédios disponíveis, mas só teve diarreia. Logo que voltou para casa não deixava nem abrir a janela; mesmo com muito calor, queria tudo fechado. Não aceitava sair de casa usando muletas, dizia que somente voltaria a sair depois de colocar a prótese:"Eu tenho vergonha disso aqui (perna amputada), não consigo aceitar isso".

Rogério trabalhava em três empregos, por opção própria. Havia noites em que não dormia, emendando um trabalho no outro. Disse que sempre foi muito agitado; não parava nunca, não ficava parado nem para conversar. O pessoal na corporação reclamava e dizia que ele não tinha conversa com ninguém. Rogério contava sobre uma inquietação que o levava a fazer coisas o tempo todo. Falava da impossibilidade de parar, o que quer que isso significasse para ele. Ao mesmo tempo, apontava para a dificuldade de estar com alguém, de se relacionar."Isso éo pior de tudo, ficar parado. A cabeça vazia é a oficina do diabo, eu fico só pensando besteira". Embora não deixasse claro a que se referiam esses pensamentos, existia algo que ele tinha que evitar: ideias, sentimentos, fantasias. Independentemente do que fosse, havia um mal-estar não formulado que provocava uma necessidade de ação constante.

Disse que quando olhava a perna sentia muita raiva da vida, do destino:"Não sei por que foi comigo, não consigo entender". Apesar de sentir que tudo estava muito difícil para ele, achava que tinha que se controlar porque tinha medo de descontar a raiva na esposa e

$\nabla \nabla \nabla \nabla$

2 Os nomes utilizados são fictícios para preservar a identidade dos pacientes. 
magoá-la. Ela Ihe dissera que o pior era vê-lo revoltado e, a partir disso, ele passou a tentar não demonstrar como se sentia: "Eu me seguro, aí quando não aguento mais, me tranco no banheiro e choro". Disse que, se não fosse assim, seria muito pior para ele, porque estava brigando muito com a esposa e "ela não merecia o que tava fazendo com ela, além disso, ninguém aguenta um cara sem perna e chato, revoltado, igual eu tô, tenho que aguentarsozinho".

Rogério usou o espaço das sessões como breves momentos nos quais pôde dizer aquilo que realmente sentia. Mostrou a angústia, o vazio, a falta de sentido que havia tomado conta de sua vida - a vergonha e o sentimento de impotência diante de seu corpo amputado - ao mesmo tempo em que disse como tentava se proteger dessa dor: sendo aquilo que entendia ser o esperado dele, ou seja, superar a perda, ficar bem com a prótese, não se revoltar, não reclamar. Tentando viver a perda da perna de uma forma diferente daquela que ele estava realmente vivendo, Rogério buscava não perder o amor de sua esposa e de seu filho e não destruí-los com sua raiva e revolta pelo que havia Ihe acontecido.

Estar amputado trazia sentimentos de profunda desvalorização, tristeza e esvaziamento do sentido da vida para Rogério. Sentia vergonha da perna amputada, afirmava que a vida não tinha mais sentido, ao mesmo tempo em que sentia muita raiva por isso ter-Ihe acontecido; não aceitava o que Ihe havia acontecido como algo próprio de sua vida, de sua história. O sentimento de impotência aparecia de forma intensa e também o medo de destruir a pessoa que estava cuidando dele e de quem se sentia dependente: sua esposa.

Em termos de desenvolvimento emocional, Rogério aproxima-se da vivência de ambivalência. Assim era com a esposa, de quem gostava e com quem queria estar, mas também com quem brigava e a quem agredia manifestando a raiva de ter perdido a perna. Porém, aproximar-se dessa ambivalência gerava muita culpa e muito medo de retaliação, que, no caso da esposa, seria deixá-lo. Para Winnicott, nas diversas formas de depressão "o paciente se encontra em dificuldades com as idéias e impulsos destrutivos que acompanham a experiência dos relacionamentos objetais" (Winnicott, 1961/1994a, p.54).

Rogério, assim como outros pacientes, falava da ausência de sentido da vida, desesperança com relação ao futuro, não reconhecimento de seu corpo como parte de si mesmo. É como se fosse não um soma, mas um corpo biológico, não personalizado.

Trata-se de uma vivência de dissociação, polarizada como depressão. O indivíduo vive a perda de uma parte do corpo como um aniquilamento de si. Não consegue apropriar-se do corpo amputado como seu; não se reconhece. A perda vivida no corpo concretiza a destrutividade contra a qual o indivíduo não consegue reagir. Nesta configuração - na qual, ao se pensar em Rogério, podem-se identificar sinais de um desenvolvimento no qual o eu não está totalmente integrado realidade externa e mundo interno se misturam; portanto, não há distinção clara entre realidade e fantasia. Assim, a destrutividade do trauma mistura-se com a agressividade própria do instinto vital e o indivíduo se depara com intenso sentimento de culpa, que gera inibição instintual como forma de defesa. Desta forma, é possível compreender o esvaziamento de sentido da vida apresentado por estas pessoas. Trata-se de depressão patológica, desencadeada por uma perda concreta diante da qual o indivíduo não encontra possibilidade de reparação.

Outro polo de reação a este tipo de perda é a negação de que algo tenha acontecido. O relato é de uma não vivência, nenhuma percepção de diferença, seja física ou emocional. A experiência dá lugar a uma racionalização sobre a experiência. Nas palavras de outro paciente: "Para mim não mudou nada, eu tô normal. Não adianta nada ficar triste, preocupado, isso não resolve nada, então eu fico bem".

Flávio tinha 29 anos, casado há dois, sem filhos. Um dia parou em um bar próximo à sua casa após o trabalho para encontrar os amigos. Entraram dois homens armados para assaltar o bar, o dono reagiu e os assaltantes atiraram. Flávio levou três tiros e fez diversos tratamentos cirúrgicos na tentativa de preservar a perna. Após seis meses teve que amputar. Na entrevista psicológica, Flávio dizia que estava tudo muito bem com ele. Não percebia nenhuma diferença após a amputação: "Pior éo cara que não vai andar nunca mais, eu vi um cara no hospital, tetraplégico, nunca mais o cara vai andar. Eu não, eu vou colocar a prótese e voltar ao trabalho". Quando questionado sobre o trabalho que realizava, pareceu a primeira oportunidade que Flávio tivera até então de se imaginar no mesmo trabalho, 
porém com uma condição física diferente: "Lá na serralheria que eu tava tem muito serviço eémeio pesado... Senão der lávou ter que procurar outra coisa, mas isso não éproblema. Eu tô de boa, essas coisas acontecem, ésó ter a menteforte, eu tô de boa".

Assim, no atendimento a pessoas amputadas, lida-se com indivíduos como Flávio, que tiveram uma perda física significativa, cuja locomoção é difícil, cuja rotina anterior à amputação encontra-se completamente alterada (isto para apontar apenas as mudanças mais concretas que a pessoa está vivendo) e que afirmam que nada mudou, que está tudo igual, que se sentem ótimos, que logo caminharão com uma prótese e será como se a perna ainda estivesse lá. Diante de um relato desse tipo não é possível reconhecer um indivíduo presente. É possível, então, pensar em algum grau de dissociação, no qual o indivíduo não reconhece como sua a vivência de ter uma perda no corpo, ou seja, ele não subjetiva a perda. Não se apropria de seu corpo como diferente do que era, uma vez que nega qualquer mudança, seja psíquica, seja dinâmica. Nesse caso, predomina o uso de defesa maníaca, na qual o sofrimento é retirado da experiência individual, ao mesmo tempo em que ocorre a exacerbação do funcionamento mental (racionalização).

A defesa maníaca manifesta-se de várias maneiras, entre elas, a negação da realidade interna, a incapacidade do indivíduo de aceitar o significado do mundo interno e a negação da vivência de depressão. Para Winnicott, faz parte da defesa maníaca o"emprego de praticamente todos os opostos na tentativa de assegurar-se contra a morte, o caos, o mistério etc., idéias que pertencem ao conteúdo fantástico da posição depressiva"(Winnicott, 1935/2000a, p.203, grifo do autor).

Se, em ambos os casos, está-se diante de algum nível de dissociação, é necessário pensar quais são os mecanismos possíveis de integração de que dispõe o ser humano em seu caminho de formação da identidade, o que remete às etapas primitivas do desenvolvimento, descritas anteriormente na conquista da unidade e, ao mesmo tempo, à função do analista como ambiente facilitador.

Não se quer afirmar com isto que toda pessoa que perde uma parte do corpo apresentará, necessariamente, esta quebra na unidade psicossomática. Isto dependerá do amadurecimento emocional alcançado por cada indivíduo e da qualidade das conquistas anteriores. Pretende-se chamar a atenção para o fato de que, na medida em que há algum tipo de dissociação, ocorre uma interrupção do processo de amadurecimento, trazendo prejuízos significativos para o indivíduo.

\section{Considerações Finais}

Nos casos citados é necessário considerar a necessidade de retomar tarefas tão iniciais quanto a temporalização e a espacialização, entendidas como redimensionamento do indivíduo em um tempo e espaço subjetivo, a elaboração imaginativa das funções do corpo, as sensações do corpo atual e o relacionamento com objetos externos, incluindo o manejo das limitações e da dependência decorrente. Assim como ocorre no desenvolvimento saudável, à medida que essas tarefas são realizadas fortalecem a identidade e o sentido de realidade do ser no mundo.

A perda de uma parte do corpo ocasiona mudanças nos indivíduos acometidos: muda o corpo, a forma de se locomover, o trabalho, o sustento pessoal e familiar, o contato social. Essas mudanças remetem à necessidade de reformulações em sua identidade para incluir esta nova dimensão de experiência. A dificuldade em realizar a elaboração imaginativa desta perda pode tornar a amputação um acontecimento não integrado na vida de uma pessoa, com consequências prejudiciais à sua saúde e ao seu desenvolvimento.

\section{Referências}

Costa, J. F. (2004). O vestígio e a aura: corpo e consumismo na moral do espetáculo. Rio de Janeiro: Garamond Universitária.

Dias, E. O. (2003). A teoria do amadurecimento de D.W. Winnicott. Rio de Janeiro: Imago Ed.

Fulgencio, L. (2006). Notas sobre o abandono do conceito de pulsão na obra de Winnicott. Winnicott E-Prints, 5 (1), p.85-95. Disponível http://www.centrowinnicott.com.br/ winnicott_eprint.

Loparic, Z. (2000). O "animal humano". Natureza Humana: Revista Internacional de Filosofia e Práticas Psicoterápicas, 2 (2), p.351-397.

Loparic, Z. (2005). Elementos da teoria winnicottiana da sexualidade. Natureza Humana: Revista Internacional de Filosofia e Práticas Psicoterápicas, 7 (2), p.311-358. 
Loparic, Z. (2006). De Freud a Winnicott: aspectos de uma mudança paradigmática. Winnicott E-Prints, 5 (1), p.1-29. Disponível http://www.centrowinnicott.com.br/ winnicott_eprint.

Mello Filho, J. (2001). O ser e o viver: uma visão da obra de Winnicott. São Paulo: Casa do Psicólogo.

Moraes, A. A. R. E. (2005). A contribuição Winnicottiana para a teoria e clínica da depressão. Tese de doutorado não- publicada, Pontifícia Universidade Católica de São Paulo.

Outeiral, J. O. (1991). Comentários sobre o conceito de psique-soma. In J. O. Outeiral \& R. B. Graña. Donald W. Winnicott estudos (pp.124-128). Porto Alegre: Artes Médicas.

Safra, G. (1993). O uso de material clínico na pesquisa psicanalítica. In M. E. L. Silva (Coord.), Investigação e psicanálise (pp.119-132). Campinas: Papirus.

Safra, G. (2005). Afaceestética do self. Teoria e clínica. Aparecida, SP: Idéias \& Letras: São Paulo: Unimarco Editora.

Winnicott, D. W. (1983). A integração do ego no desenvolvimento da criança. In: Winnicott, D.W. O ambiente e os processos de maturação: estudos sobre a teoria do desenvolvimento emocional (pp.55-61). Porto Alegre: Artes Médicas. 1983. (Originalmente publicada em 1962).

Winnicott, D. W. (1994a) Psiconeurose na infância. In D. W. Winnicott. Explorações psicanalíticas (p 53-58). Porto Alegre: Artes Médicas. (Originalmente publicada em 1961).
Winnicott, D. W. (1994b). Fisioterapia e relações humanas. In D. W. Winnicott. Explorações psicanalíticas (pp.427-432). Porto Alegre: Artes Médicas. (Originalmente publicada em 1969).

Winnicott, D. W. (1994c). Individuação. In D. W. Winnicott. Explorações psicanalíticas (pp.219-222). Porto Alegre: Artes Médicas. (Originalmente publicada em 1970).

Winnicott, D. W. (2000a). A defesa maníaca. In D. W. Winnicott. Da Pediatria à Psicanálise: Obras Escolhidas (pp.199-217). Rio de Janeiro: Imago Ed. (Originalmente publicada em 1935).

Winnicott, D. W. (2000b) Desenvolvimento emocional primitivo. In D. W. Winnicott. Da pediatria à psicanálise: obras escolhidas (pp.218-232). Rio de Janeiro: Imago Ed. (Originalmente publicado em 1945).

Winnicott, D. W. (2001). O primeiro ano de vida. Concepções modernas do desenvolvimento emocional. In D. W. Winnicott, D.W. A família e o desenvolvimento individual (pp.3-20). São Paulo: Martins Fontes. (Originalmente publicada em 1958).

Winnicott, D. W. (2005). Variedades de psicoterapia. In D. W. Privação e delinqüência (p. 263-273). São Paulo: Martins Fontes. (Originalmente publicada em 1961).

Recebido em: 17/2/2007

Versão final reapresentada em: 28/4/2008

Aprovado em: 9/6/2008 